\title{
Effect of Improving the Slip Properties of the Organic Materials on the Inorganic Filler in Heat Dissipated Pad
}

\author{
Meehye Oh, Yeoseong Yoon, Dongjoon Moon, Eunjin Jang \\ Innopolis Research and Development Corps, Innopolis Campus, Korea Automotive Technology Institute, Cheonan Chungnam, Korea \\ Email: mhoh@katech.re.kr
}

How to cite this paper: Oh, M., Yoon, Y., Moon, D. and Jang, E. (2021) Effect of Improving the Slip Properties of the Organic Materials on the Inorganic Filler in Heat Dissipated Pad. Materials Sciences and Applications, 12, 595-602.

https://doi.org/10.4236/msa.2021.1212039

Received: November 17, 2021

Accepted: December 21, 2021

Published: December 24, 2021

Copyright ( 2021 by author(s) and Scientific Research Publishing Inc. This work is licensed under the Creative Commons Attribution International License (CC BY 4.0).

http://creativecommons.org/licenses/by/4.0/

\begin{abstract}
The heat dissipated pad is made of composite mixing silicon or epoxy resin with thermal conductive inorganic fillers. The heat-dissipation material improves performance as the amount of thermal conductivity filler increases. However, the optimum recipe should be determined by considering the price and pad formability. In this study, high performance thermal pad is made of silicon resin mixed with $\mathrm{Al}_{2} \mathrm{O}_{3}$ as a thermally conductive filler. Since $\mathrm{Al}_{2} \mathrm{O}_{3}$ is low cost, it can use much filler. $\mathrm{Al}_{2} \mathrm{O}_{3}$ has improved slip-ability with organic coating on it to increase the viscosity of the slurry. The same process and the same recipe, could maximize the amount of the filler. As a result, the thermal conductivity is lower by $10 \%$. But the viscosity is reduced by $60 \%$, too. So form-ability is getting priority.
\end{abstract}

\section{Keywords}

Slip Property, Organic Coat, Slurry Flow-Ability, Thermal Conductivity, Heat Dissipated Pad

\section{Introduction}

As high-power LED lighting and related electronics industry are growing, the high-performance and high-integrated electronic devices are increasing. Electronic devices can cause system error or shorten the life due to heat generated during the running. Therefore, heat-dissipation, which can prevent fire or explosion, is an important technology in an electronic device [1] [2].

Heat sinks are commonly used but the heat dissipated sheets are also used to reduce the volume [1]. The heat dissipated sheet has classified grade depending on the thermal conductivity, which is used according to the performance 
of the target [2].

In automotive technology, it is needed to deal with generated heat from electronic control units such as the IGBT (Insulated Gate Bipolar Transistor) and Power IC. Motor output is increasing to improve the performance of HEV or EV. Related to this, power system is minimizing heat accumulation inside by increasing thermal conductivity of silicon in component material. The thermal conductive silicon composite is required to have flow-ability, wettability, adhesion and fast curing. Silicon is a highly reliable and durable material. Therefore, it is possible to apply in various fields such as automotive, electronics and industrial use [1].

In this study, the insulated thermal pad has been manufactured and evaluated. The organic material coated on the $\mathrm{Al}_{2} \mathrm{O}_{3}$ can improve the viscosity to facilitate form-ability. However, thermal conductivity may be lowered by the organic coating layer. Therefore, we proposed a method of developing high performance sheet by control of viscosity and thermal conductivity.

\section{Methods}

The heat dissipation pad was produced by mixing silicone resin and alumina powder [1] [2]. The heat dissipated pad is very important choosing of filler because a large amount of filler must be contained. The price of functional filler is a very important factor because it uses approximately 700 to $800 \mathrm{phr}$ in heat dissipated pad. The $\mathrm{Al}_{2} \mathrm{O}_{3}$ is both plate and spherical, and the particle size is tens or hundreds micrometers. In case of the plate types $\mathrm{Al}_{2} \mathrm{O}_{3}$, thru-plane thermal conductivity is low. And there may be a disadvantage to forming a thermal path. In order to make the heat transfer path well, a composite material was prepared by mixing plate-shaped and spherical fillers. The voids can be minimized by using various sizes of spherical $\mathrm{Al}_{2} \mathrm{O}_{3}$. By mixing the shape and size in this way, packed property of filler can be enhanced (Therefore, it can be improved packing properties). It is necessary to consider the effect of fillers for conductivity as it is oriented in the process of rolling the thermal pad [1] [2]. The $\mathrm{Al}_{2} \mathrm{O}_{3}$ is coated with water soluble acrylic emulsion by Fine Chem Tech Co. The coated $\mathrm{Al}_{2} \mathrm{O}_{3}$ and silicon liquid resin (HRS Co.) were mixed and then it was cured to pad. The cured pad was measured its hardness, insulation characteristics and thermal conductivity.

The organic layer on $\mathrm{Al}_{2} \mathrm{O}_{3}$ was coated by mixed acrylic emulsion and catalyst. It was stirred for $1000 \mathrm{rpm}$ during 30 minutes again by adding aqueous acrylic emulsion after stirring $800 \mathrm{rpm}$ for $5 \mathrm{~min}$ in distilled water with the catalyst. The coating layer was observed according to curing conditions as like temperature and curing time. We were cured at $60^{\circ} \mathrm{C}, 100^{\circ} \mathrm{C}, 130^{\circ} \mathrm{C}$ and $150^{\circ} \mathrm{C}$ for 30 minutes or 1 hour [1]. The coating layer of each condition was analyzed by FT-IR (IS5 from Thermo) and SEM. It was showed the coating procedure in Figure 1 [1] [2].

The thermal pad is made of silicon resin with coated $\mathrm{Al}_{2} \mathrm{O}_{3}$. We used planetary mixer by THIKKY ARE310, for mixing and degassing [3]. It was measured viscosity for slurry and thermal conductivity for sheet. The thermal conductivity was 


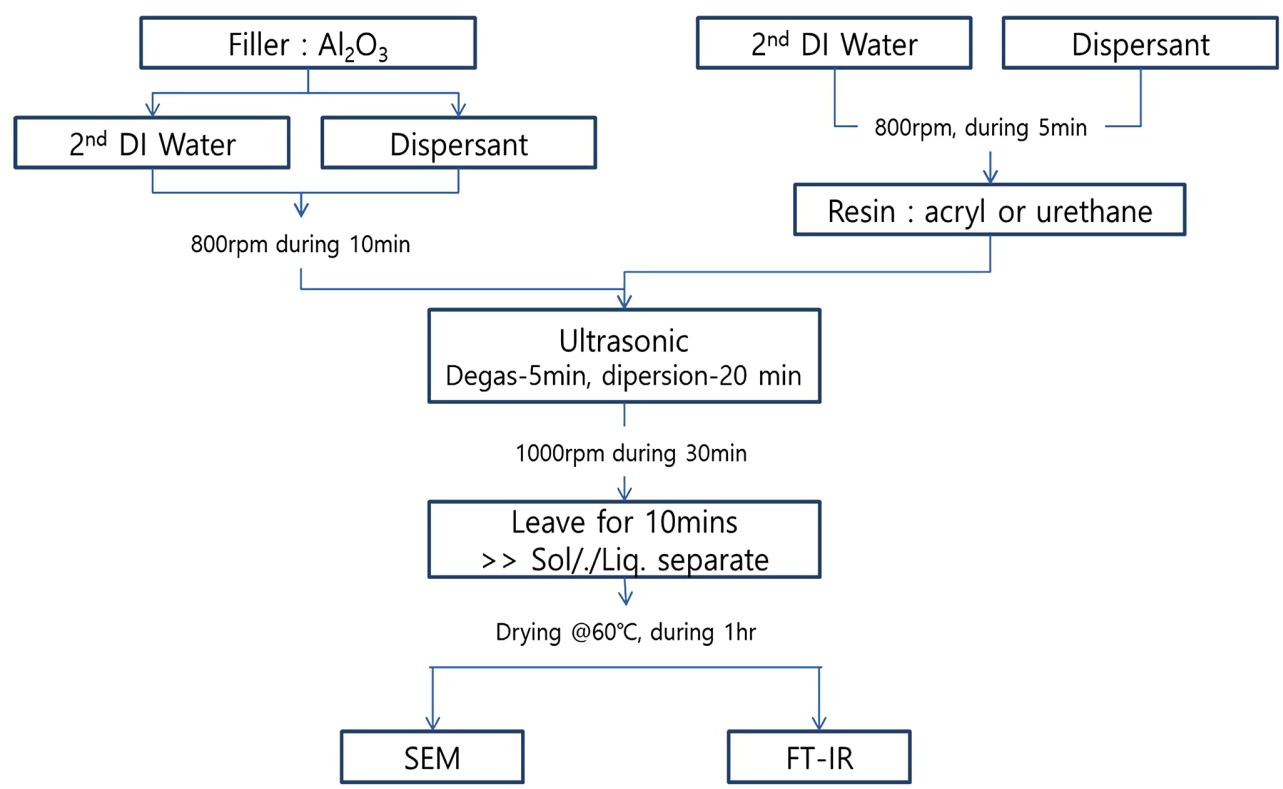

Figure 1. The coating procedure for alumina.

measured by the heat flow meter (Anter Co. UNITHERM ${ }^{\circledR} 2022$ ) method in ASTM E1530 standard. A thermal pad is held under even compressive load between two plates of 10-degree difference. The heat flows from the upper surface, through the thermal pad, to the lower surface, establishing a directional thru axial temperature gradient in the stack. After reaching thermal equilibrium, the heat resistance of thermal pad was measured from the heat flow transducer. The thermal conductivity was calculated by dividing the thermal resistance by the thickness of thermal pad.

\section{Results and Discussion}

\subsection{Materials}

The water-based acrylic emulsion used as coating solution has a similar structure to silicon resin. Similarity of molecular structure may increase the compatibility of coating layer and matrix resin. The more filler amount there is, the lower flow-ability it is. The interface of uncoated filler and resin were separated and the void was formed. Thus, the composite has degraded. The organic-inorganic interface could be stabilized by the coating layer [1] [2]. We carried out FT-IR analysis for the coated layer by water-based acrylic emulsion with $5 \%$ curing agent.

Figure 2 shows the result of the FT-IR spectrum. The OH stretching vibrations peak at the range of $3200-3550 \mathrm{~cm}^{-1}$, was shown only in curing condition at $60^{\circ} \mathrm{C}$ duration of 30 minutes. Graph (c) shows $\mathrm{CH}$ spectrum at $2880-2900$, $\mathrm{CH}_{2}$ spectrum at $2843-2863 \& 2916-2936 \mathrm{~cm}^{-1}$ and the conjugated $\mathrm{C}=\mathrm{O}$ spectrum at $1590-1750 \mathrm{~cm}^{-1}$ range. For the cured coating layer at $130^{\circ} \mathrm{C}$, the $\mathrm{C}=\mathrm{C}$ stretching vibration peak at $1620-1680 \mathrm{~cm}^{-1}$ disappeared.

The coating layer on the $\mathrm{Al}_{2} \mathrm{O}_{3}$ formed thickness and surface status according to the recipe of coating solution [1] [2]. The lower the water-based acrylic 

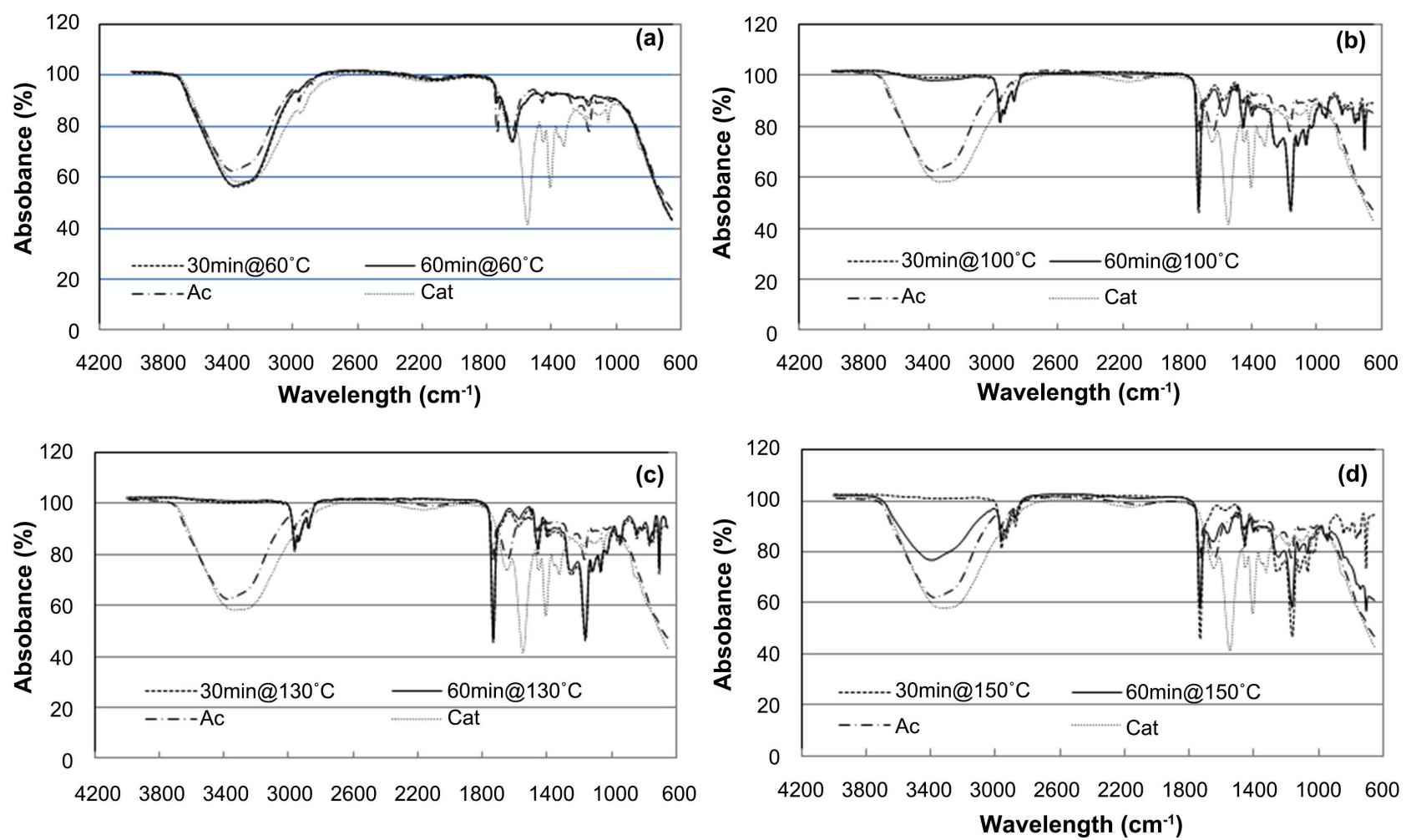

Figure 2. IR spectrum by curing temperature and time.

emulsion concentration, coated the thinner layer, but it is difficult to the uniform organic coating layer. The amount of the spherical $\mathrm{Al}_{2} \mathrm{O}_{3}$ was kept constant and the amount of the water-based acrylic emulsion was changed to $50-70 \mathrm{wt} \%$. Because it was used as a weight ratio, coating area of $\mathrm{Al}_{2} \mathrm{O}_{3}$ varies depending on the particle distribution. Figure 3 shows the surface before and after the coating on the $\mathrm{Al}_{2} \mathrm{O}_{3}$. The (a) SRA series has a bumpy surface that looks like woven fibers and (b) DAB series appears to be entangled with fine particles on the surface of the spherical particle. Finally, (c) SA series formed a spherical with overlapped plated was showed the form in which the plate overlapped to form a spherical. The surface shape of $\mathrm{Al}_{2} \mathrm{O}_{3}$ is formed differently according to the manufacturing process. After coating, the surface of $\mathrm{Al}_{2} \mathrm{O}_{3}$ shows. (a) formed in a thick and uneven layer, and (b) the fine particles in coating layer are densely entangled. (c) are observed to smooth particle edges maintaining the shape.

Figure 4 shows the composite process of coated $\mathrm{Al}_{2} \mathrm{O}_{3}$ and silicon resin. The thermal conductivity of the heat dissipation pad varies with the amount of the filler. As the amount of filler increases, the thermal conductivity increases, but the manufacturing process becomes difficult. It is difficult to control thickness and smoothness depending on the viscosity of the composite slurry. Therefore, the control of viscosity is key technology in sheeting process. Slurry with a lot of filler requires to prevent aggregation or tangle during the high speed mixing and degassing [1] [2]. The use of a high-speed mixer, may be separated inorganic filler and organic resin due to density differences or be whirlpool. In this study, it 


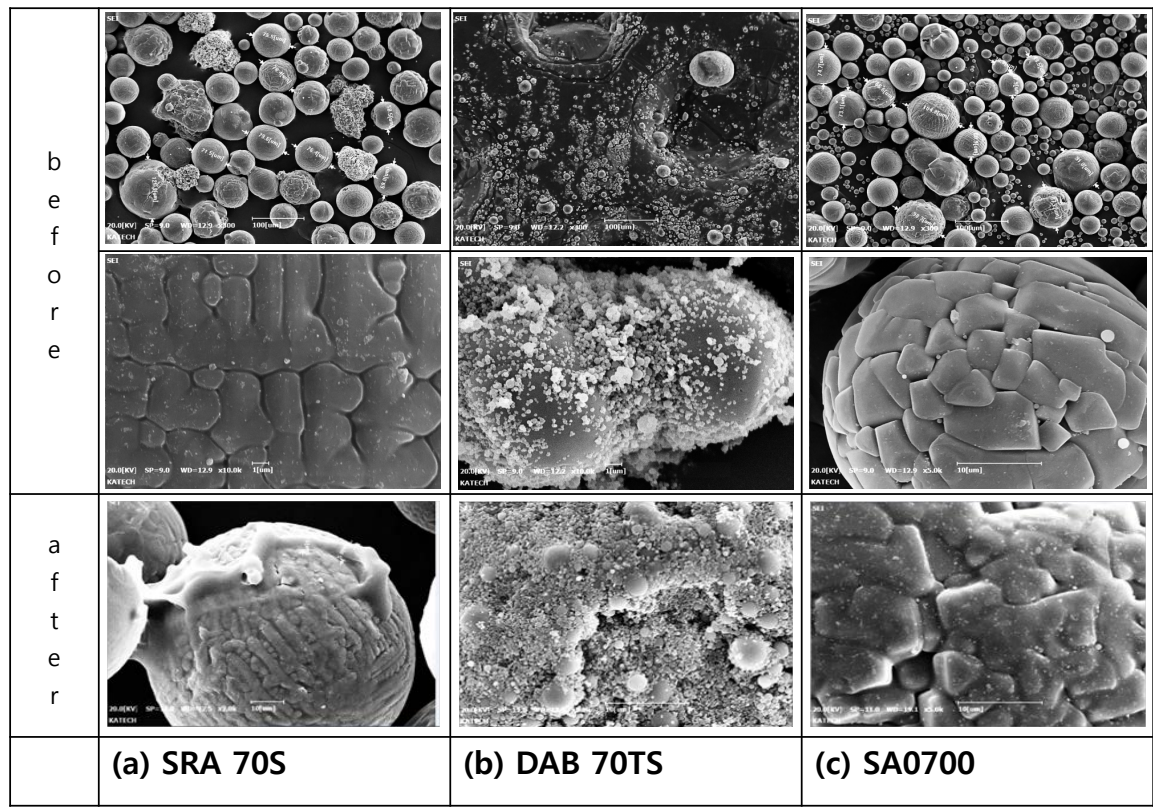

Figure 3. SEM image of alumina: before and after surface treatment.
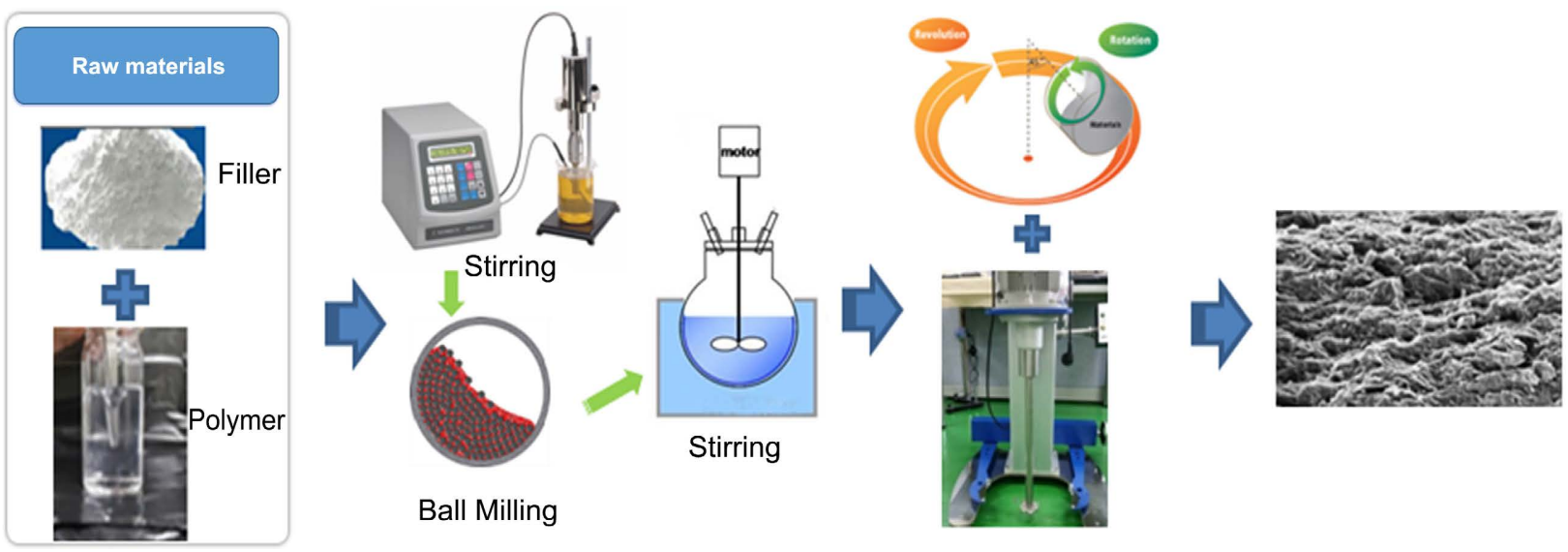

Figure 4. Manufacturing process of slurry for thermal pad.

compounded the homogenous slurry by the planetary mixer and then manufactured a sheet containing a filler of $600-800 \mathrm{phr}$.

\subsection{Thermal Conductivity \& Viscosity}

The thermal conductivity was measured by the heat flow method (Anter Co. UNITHERM $^{\circledR} 2022$ ) in the bulk thru value. The thermal conductivity of thermal pad is important. The thermal pad is important to thermal conductivity. Thermal conductivity for the directional bulk thru is important in the thermal pad. The compatibility between filler and resin has a major influence on the flowability of slurry [4]. In this study, it was coated with a silicone resins similar material to increase the mixing limit amount of $\mathrm{Al}_{2} \mathrm{O}_{3}$ in composite. The viscosity was compared for slurry using uncoated and coated $\mathrm{Al}_{2} \mathrm{O}_{3}$. The thermal path was cut off by the organic interfacial layer [1] [2]. However, the thin coating layer did 
not completely block the heat transfer. The rate of heat transfer can be determined according to the thickness of the coating layer. It is not easy to measure the thickness of the coating layer on the filler. The thickness of the coating layer was estimated from the amount of coating solution. From this, it was analyzed relationship the thickness of coating layer and thermal conductivity. Table 1 shows the effect of the coated filler in composite material of its amount. The thermal conductivity and viscosity of composite with $600-800$ phr $\mathrm{Al}_{2} \mathrm{O}_{3}$ are shown in Figure 5.

The higher the coated filler content, the lower the thermal conductivity by up to maximum $10 \%$ and the lower the viscosity by about $60 \%$. In order to increase thermal conductivity of the thermal pad, the filler content should increase. But the composite of inorganic and organic materials is inhibited its flowability because of its low compatibility. As the amount of filler in composite increases, the viscosity increases [3] [4]. Therefore, it is hard to make the pad. By the coating layer that has a similar property to matrix resin on the surface of the $\mathrm{Al}_{2} \mathrm{O}_{3}$, the flow-ability is increased by the improved compatibility. For higher thermal conductivity, it is effective to increase the filler. The higher thermal conductivity can

Table 1. Properties of composite sheet by component.

\begin{tabular}{|c|c|c|c|c|}
\hline \multicolumn{2}{|c|}{ Filler } & \multirow{2}{*}{$\begin{array}{c}\text { Thermal } \\
\text { Conductivity } \\
(\mathrm{W} / \mathrm{m} \cdot \mathrm{K})\end{array}$} & \multirow[b]{2}{*}{ Density } & \multirow{2}{*}{$\begin{array}{c}\text { Viscosity } \\
\text { (cP) }\end{array}$} \\
\hline Amount (phr) & $\begin{array}{c}70 \mu \mathrm{m} \mathrm{Al} \mathrm{O}_{3} \\
\text { Status of coating }\end{array}$ & & & \\
\hline \multirow{2}{*}{600} & - & 2.10 & 2.74 & 84,100 \\
\hline & $\mathrm{O}$ & 1.85 & 2.64 & 48,400 \\
\hline \multirow{2}{*}{700} & - & 2.70 & 2.79 & 257,300 \\
\hline & $\mathrm{O}$ & 2.54 & 2.73 & 65,910 \\
\hline \multirow{2}{*}{800} & - & 3.23 & 2.86 & 790,000 \\
\hline & $\mathrm{O}$ & 2.88 & 2.81 & 288,400 \\
\hline
\end{tabular}

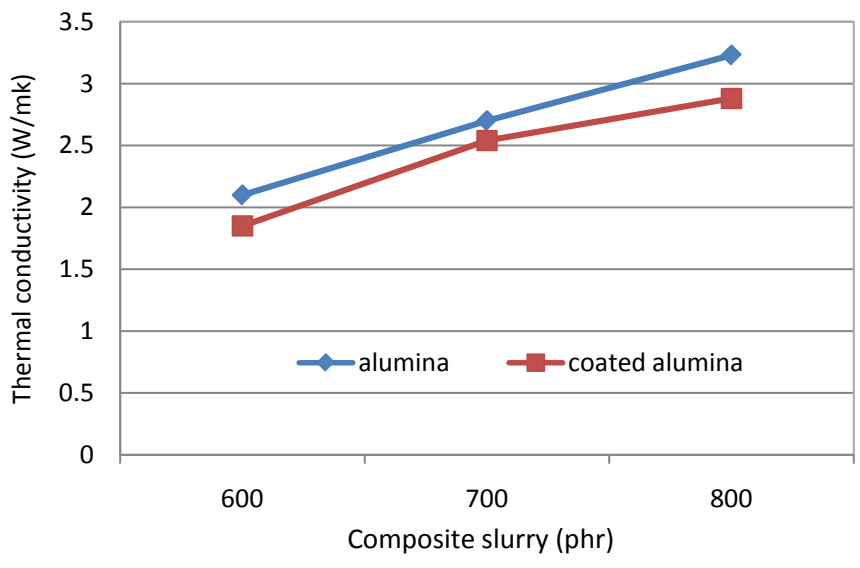

(a)

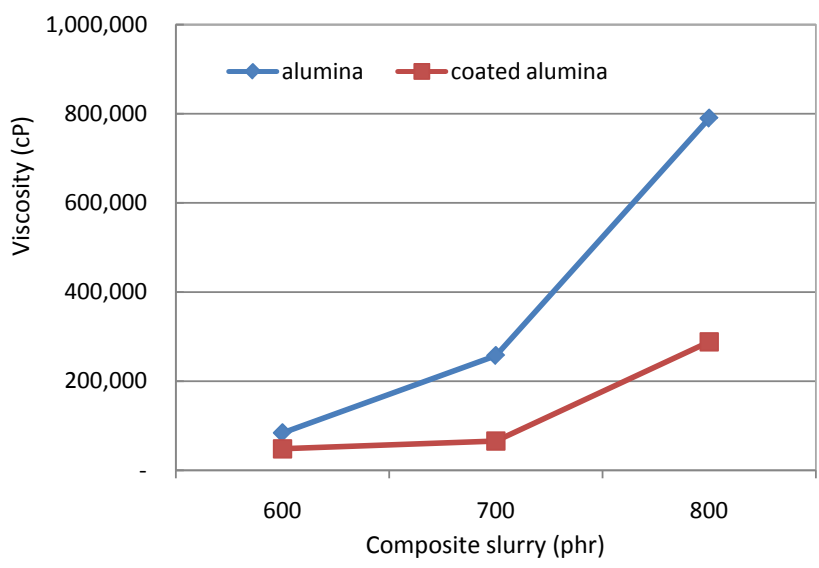

(b)

Figure 5. Proeprties by amount of filler in slurry. (a) Thermal conductivity; (b) Viscosity. 
be obtained if the functional filler has more filler in the same viscosity for manufacturing process [1] [2]. The thermal conductivity of thermal pad containing $600-800 \mathrm{phr} \mathrm{Al}_{2} \mathrm{O}_{3}$ was $2-3 \mathrm{~W} / \mathrm{m} \cdot \mathrm{K}$. The same amount of filler, $600 \mathrm{phr}$, the thermal conductivity is $2.10 \mathrm{~W} / \mathrm{m} \cdot \mathrm{K}$ for uncoated $\mathrm{Al}_{2} \mathrm{O}_{3}$ and $1.85 \mathrm{~W} / \mathrm{m} \cdot \mathrm{K}$ for coated $\mathrm{Al}_{2} \mathrm{O}_{3}$.

But the viscosity is $84,100 \mathrm{cP}$ for uncoated $\mathrm{Al}_{2} \mathrm{O}_{3}$ and $48,400 \mathrm{cP}$ for coated $\mathrm{Al}_{2} \mathrm{O}_{3}$. The viscosity was $42 \%$ lower than thermal conductivity. In the case of using coated $\mathrm{Al}_{2} \mathrm{O}_{3}, 700 \mathrm{phr}$, the viscosity is $65,910 \mathrm{cP}$ and the thermal conductivity is $2.54 \mathrm{~W} / \mathrm{m} \cdot \mathrm{K}$. As a result, it should be decided after comparing the improvement of thermal conductivity and viscosity. The coated filler has a low viscosity, which can increase its quantity. This has a greater effect than the thermal conductivity loss.

\section{Conclusions}

Through this study, the following conclusions were obtained.

Slurry composite materials were manufactured using $\mathrm{Al}_{2} \mathrm{O}_{3}$ and silicon resin. $\mathrm{Al}_{2} \mathrm{O}_{3}$ was coated with aqueous acrylic emulsion to improve slip-ability. Organic coating layer improves slip-ability due to its interfacial characteristics with resin, but the thermal path of $\mathrm{Al}_{2} \mathrm{O}_{3}$ was disconnected. Coated $\mathrm{Al}_{2} \mathrm{O}_{3}$ and silicon resin were mixed by a high-speed mixer. And then, the thermal pad was made of slurry. Before and after coating was characteristics used $\mathrm{Al}_{2} \mathrm{O}_{3}$ of the same amount.

The composite with the same amount of $\mathrm{Al}_{2} \mathrm{O}_{3}$ was used before and after coating. When using the uncoated $\mathrm{Al}_{2} \mathrm{O}_{3}(600 \mathrm{phr})$, the thermal conductivity of the sheet using the $84,100 \mathrm{cP}$ slurry was $2.1 \mathrm{~W} / \mathrm{m} \cdot \mathrm{K}$. When using coated $\mathrm{Al}_{2} \mathrm{O}_{3}$ ( $600 \mathrm{phr}$ ), the thermal conductivity of the sheet from $48,400 \mathrm{cP}$ slurry was 1.85 $\mathrm{W} / \mathrm{m} \cdot \mathrm{K}$. When $700 \mathrm{phr}$ of coated $\mathrm{Al}_{2} \mathrm{O}_{3}$ filler is used, the viscosity of the slurry is $675,910 \mathrm{cP}$ and the thermal conductivity of the sheet is $2.5 \mathrm{~W} / \mathrm{m} \cdot \mathrm{K}$.

The improvement of viscosity was shown to be a greater effect than the degradation of thermal conductivity.

\section{Acknowledgements}

This paper is the result of industrial core technology development project supported by Ministry of Commerce, Industry and Energy jointly and VIZTRO MILTECH Co.

\section{Conflicts of Interest}

The authors declare no conflicts of interest regarding the publication of this paper.

\section{References}

[1] Moon, D.J., Yoon, Y.S., et al. (2017) A Study on the Thermal Conductivity Properties of Thermal Sheets According to Coatings that Improve the Slip Properties of Inorganic Fillers. Theories and Applications of Chemical Engineering, 23, 1425 p. 
[2] Yoon, Y.S., Oh, M.H., et al. (2018) A Study of Heat Dissipation Pad Characteristics Using Fine Surface Modified Alumina Using Silane. Theories and Applications of Chemical Engineering, 24, 8 p.

[3] Huzzard, R.J. and Blackburn, S. (1998) Slip Flow in Concentrated Alumina Suspensions. Powder Technology, 97, 118-123.

https://doi.org/10.1016/S0032-5910(97)03397-4

[4] Mahdavi, M., Sharifpur, M. and Ghodsinezhad, H. (2017) A New Combination of Nanoparticles Mass Diffusion Flux and Slip Mechanism Approaches with Electrostatic Forces in a Natural Convective Cavity Flow. International Journal of Heat and Mass Transfer, 106, 980-988.

https://doi.org/10.1016/j.ijheatmasstransfer.2016.10.065 